\title{
Research on the Mechanism of Cooperative Education: Collaboration Between Private Universities and Private Companies
}

\author{
LI Dehui 1,a, ${ }^{1}$, XIE Xiaoli ${ }^{2, b}$, and QI Yanxin ${ }^{3, c}$ \\ ${ }^{1}$ Zhuhai Campus of Beijing Institute of Technology, Zhuhai, Guangdong, China \\ ${ }^{2}$ Chang'an University, Xi'an, Shaanxi, China \\ 3 Zhuhai Campus of Beijing Institute of Technology, Zhuhai, Guangdong, China \\ anewdhl@yeah.net, ㅁxiaoli@chd.edu.cn, ㅁaiyx64@163.com \\ ${ }^{*}$ Corresponding author
}

Keywords: Private University, Cooperative education, mechanism.

\begin{abstract}
Private universities inherited the property rights structure of diversification of non-government education, low-cost advantages and flexible mode of operation. However, because of the short setup time, they lack experience, and their ability of fulfilling social needs is insufficient. Transportation private enterprises have sprung up in the big tide of rapid industry development, facing the problem of human resources shortage. This paper takes transportation engineering as a case, and focuses on the innovation in collaboration between private enterprise and private universities, to effectively promote enterprise technical update and enhance the ability to manage and improve the education system of private universities. The study and practice on the mechanism of cooperative education have a great significance for enhancing the comprehensive competitiveness of enterprises and the teaching quality in universities.
\end{abstract}

\section{Introduction}

With the promotion of the "The Belt and Road Initiatives" strategy and the increasing urban traffic problems, the requirement for professionals in transportation becomes higher. Private universities, such as ZHBIT (Zhuhai Campus of Beijing Institute of Technology), inherited the property rights structure of diversification of non-government education, low-cost advantages and flexible mode of operation. However, because of the short setup time, these private universities lack experience, and their ability of fulfilling social needs is insufficient. Transportation private enterprises have sprung up in the big tide of rapid industry development, facing the problems of human resources shortage, poor management and weak ability to resist risks. The public universities do not take serving private enterprises as their priority. Therefore, the study focuses on the innovation in collaboration between private enterprise and private universities, to effectively promote enterprise technical update and enhance the ability to manage and improve the education system of private universities. The main targets are 1) to build a cooperative mode that can involve research, technology and skilled talents cultivation in education and 2) to explore the innovation mechanism of cooperation with private enterprise focused on student cultivation.

\section{Guiding Ideology and Principles}

Because the universities and enterprises have different interest demand and due to policy-oriented reasons, the private universities focus more on academic theoretical achievements, and put less emphasis on market development research. Most of the enterprises are implementing contract system, which results in the pursuit of short-term profit, rather than investment in long-term innovation. To change this trend, the core approach is to change the mechanism. This includes that each demand of universities and enterprises has to be taken into account, meanwhile letting market allocate recourses and make policies to create favorable environment on school-enterprises coordination. Furthermore, it is required to establish school-enterprise collaborative innovation evaluation system, and build 
rewards system and set up strategy entities as innovative platform. In the selection of cooperative enterprises, private universities need to base on their own positioning and orientations to choose their own collaborative partners and corresponding mode. In the mechanism of cooperative and operational system, private universities need to play a flexible role to break the routine so as to promote school-enterprise resource sharing, make joint-research project into a profitable point. According to the core principle, five detailed distinctive mechanism are applied in transportation engineering: platform mechanism, complementary mechanism, hiring and training mechanism, income distribution mechanism, innovation entrepreneurship mechanism.

\section{Distinctive Mechanism}

3.1 Strategy Entity (Platform Mechanism). China has taken great emphasis on collaborative innovation. This requires both sides pool resources and overcome difficulties; only in this way we can gain a breakthrough of innovation in key areas. In order to realize the educational target, a collaboration platform acts as a trigger. In this background, the strategy entity "Transportation Development Collaborative Innovation Center (TDCIC), Pearl River Delta" is established. The members in TDCIC are representative enterprises in transportation fields in Pearl River Delta, including Guangzhou U-control information technology co., LTD. (Guangzhou U-control for abbr.), Zhuhai transportation survey and design institute co., LTD (ZTSDI for abbr.) and municipal engineering institute of Shenzhen architectural design institute co. LTD (i.e., Shenzhen Tianyi municipal engineering design institute co., LTD. SADI for abbr.). Each company occupies a dominant position within the subdivision field of transportation.

3.2 Complementary Mechanism. Transportation engineering is an interdisciplinary major, involving highway and urban road, rail transit, transportation operations, aviation navigation, port and other modes of transport. Transportation is closely linked to road and bridge engineering, civil engineering, computer science, urban planning, etc. In the past two years, the rise of big data science has rephrased to the development of traffic engineering.

Every private enterprise in TDCIC has the commonality of business and mutual cooperation that can achieve the good result in "integral function is greater than the sum of the partial function", or in other words " $1+1>2$ " effect. Currently, members in TDCIC have obvious advantage in education research (ZHBIT), traffic signal control and traffic information processing (Guangzhou U-control), road and traffic engineering design (ZTSDI), road and municipal engineering (SADI), and they have achieved reputation in Pearl River Delta area. So the members have good win-win cooperation foundation.

3.3 Hiring and Training Mechanism. The purpose of establishment of TDCIC is to break barriers, so that the talents can be used by various purposes. The professors can be a project leader in the collaborative innovation platform, while engineers can be employed by the university to act as a part-time professor and teach student with their engineering experiences. This way of talent resource sharing can effectively avoid vicious competition for high-level talents and losses. It can also save a lot of money by equipment sharing.

Improving the mechanism of scientific research personnel employment system allows the TDCIC to play a leading and exploratory role in innovating of scientific research personnel employment, set up research posts flexibly based on research tasks. Exploring ways establishes personnel hiring new mode "double employment", "contract employment", "labor contract" and so on in members of TDCIC, so as to achieve "total fitness is positioned by business, people post, structure optimization". 3.4 Income Distribution Mechanism. TDCIC will be a platform for all the members to apply provincial projects. Therefore, reasonable income distribution mechanism will be a key point for cooperation and project running. So the assessment mechanism should be reasonable and diversified and neither in accordance with the standard for college teachers, nor according to the enterprise assessment method. The purpose of the new assessment is to ensure that scientific research can be carried on smoothly and in accordance with research and education goals of TDCIC. At the same time, clear the income distribution mechanism of definite achievements. The earning of assignment should 
be reasonably distributed between the important contribution and scientific research institutions. The earning should be used to reward research director, core technical personals and important contributors of achievements and team, which is no less than $50 \%$ of revenue. The rewards for researchers should be over $50 \%$, and the provisions distribution should be discussed in form of contract in negotiation with college enterprises and TDCIC. The rewards should be directly included in income of the scientific researchers, but not included in the performance salary management.

3.5 Innovation Entrepreneurship Mechanism. Based on TDCIC and the respond to the appeal by the state, deepen innovation entrepreneurship system, combined with the related policies about provinces and cities innovation entrepreneurship, school innovation entrepreneurship related system must be practicable, and create favorable conditions for teachers and the students. Also, it needs to provide the support for teachers in building project teams and entering college business Incubation Park. The team members can include members from any college, company from TDCIC. The university should provide appropriate services and conditions like logistics, scientific research, trial production and so on. Also, it should allow teachers with strong academic and research capabilities to take part-time positions in enterprises or open their own business on the premise that the teachers have the education responsibilities performed seriously. Allows the students who have strong innovation ability and have certain conditions to start an innovation entrepreneurship or take intern in TDCIC, and encourage them to enter incubation center, the university is responsible to provide favorable measure and supporting services. TDCIC will provide technical support.

\section{The Preliminary Achievements of Collaboration Platform}

4.1 Qualified as EQP. With the support of TDCIC, transportation engineering was qualified as Education Quality Project (EQP) in 2015. The ultimate goal of this project is to provide qualified talents for transportation, highway construction, operation, ITS in Guangdong province, and dedicate to supply talents for local social and economic demand on infrastructure construction, to provide intellectual support for Guangdong and Zhuhai as an important node in the " the Belt and Road Initiatives".

4.2 Double-qualified Teachers. Now there are teachers who are involved in tasks in enterprises during vacations, take advantage of the theory combined with practice so as to improve teachers' quality and improve the level of future teaching. At the same time, establish off-campus mentor group, give lectures and seminars through aid from front-line technician in TDCIC, and realize the object of shortening the distance of the college and society.

4.3 Breakthrough in Scientific Research. Carry out cooperation scientific research mechanism, through the complementary advantages of the members, TDCIC has undertaken two research projects, (Foshan road traffic simulation modeling and Zhuhai Pingsha new town construction projects), income distribution mode has been explored in the project operations.

3.4 Students Joint Cultivation. Carry out students Order-style pattern to meet the need of local transportation enterprises and government. That is the students who study basic and professional courses in the first three years, but the curriculum and teaching plan of the fourth year are designed according to the actual needs of enterprises, and dynamically revised in accord with the change of social needs. We have pilot order-style pattern experiment cooperative with Guangdong U-control and the responses from students are fairly positive.

4.5 Students Competition. To implement the concept of support for innovation and Entrepreneurship, a joint group (the university and ZTSDI) has been built up to take part in the 2016 "Internet+transportation" innovation and entrepreneurship competition held in Guangzhou and won the third place. Now the team has entered the college Incubation Park.

\section{Summary}

This paper describes the collaborative innovation road between private enterprises and private universities, take collaborative innovation and education center as a platform, the platform 
mechanism, the complementary mechanism, hiring and training mechanism, income distribution mechanism and innovative entrepreneurial mechanism are studied. Pilot study and practice has been made in research project cooperation, student joint cultivation, double-qualified teachers. Some achievements have been made in last three years, and the practical experience is not only very important to the student's cultivation, but is good to the enterprises.

\section{Acknowledgement}

This research was financially supported by the Fund on Guangdong Province Characteristic Innovation Project (Educational Scientific Research), Supported by Education Bureau of Guangdong Province (Grant NO. 2015GXJK179).

\section{References}

[1] L. Yang. The practical path of cultivating innovative talents by school enterprise cooperation, Heilongjiang Researches on Higher Education, vol1, pp.62-65, 2013

[2] X.L. XIAO. Synergetics - Based research on school-enterprise synergetic development of multiple platform, Modern Education Management, vol1,pp.39-42, 2014

[3] T. Xu. On innovation in mechanism of school-company cooperation, Education Development Research, vol17,pp.64-69, 2012

[4] X.L. CAI. Exploration and thinking on the talent training mode of college enterprise cooperation, Education and Vocation, vol1, pp.72-74, 2012

[5] T.Z. CAI and D.G. CAI. Problems and Countermeasures of cultivating high skilled talents by school enterprise cooperation, Heilongjiang Researches on Higher Education, vol5, pp.137-139, 2012

[6] J.M. LI. The Practice of the market-centered educational mode in local universities, Journal of Yangzhou University(Higher Education Study Edition), vol14,pp.11-14, 2010 